\title{
DESCENTRALIZAÇÃO DA GESTÃO AMBIENTAL NO BRASIL: ANÁLISE HISTÓRICA DOS PRINCIPAIS MOMENTOS DO PROCESSO
}

\author{
DECENTRALIZATION OF ENVIRONMENTAL \\ MANAGEMENT IN BRAZIL: HISTORICAL ANALYSIS \\ OF THE KEY MOMENTS OF THE PROCESS
}

Arthur Caldeira Sanches ${ }^{1}$; Mary Fernanda Sousa Melo ${ }^{2}$ Willerson Lucas Campos-Silva ${ }^{3}$; Silvia Morales de Queiroz Caleman ${ }^{4}$

Recebido em: 10 de fevereiro de 2017 Aprovado em: 25 de abril de 2017 Sistema de Avaliação: Double Blind Review RGD | v. 14 | n. 2 | p. 51-67|jul./dez. 2017

\begin{abstract}
RESUMO
Devido à preocupação mundial quanto à temática gestão ambiental, os países passaram a buscar formas de proteger suas riquezas naturais através de políticas e práticas de gestão ambiental em seus territórios. Visando a maior eficiência do processo de gestão observa-se a descentralização dos poderes do Governo Federal para os estados e municípios. A criação de políticas ambientais surgiu no Brasil a partir da Lei 6.938/81, mas apenas com a Constituição de 1988 que o processo de descentralização teve início. Devido à crescente importância do tema, fazem-se necessários estudos que busquem detalhar e descrever o processo da gestão ambiental no país. Este estudo é de caráter exploratório descritivo, tendo como objetivo principal a análise de como a descentralização da gestão ambiental ocorreu no país, trazendo alguns de seus principais pontos. Através dos dados coletados, concluiu-se que a discussão sobre o meio ambiente teve seu início mais especifico em 1920/1930, e, apesar de terem importantes marcos em 1960 e 1970, foi apenas a partir da década de 80 que se iniciaram as políticas ambientais e seu processo de descentralização. Atualmente o país se encontra em processo de criação de secretarias e órgãos especiais em cada estado visando uma maior descentralização da gestão.
\end{abstract}

Palavras-chave: Descentralização. Gestão Ambiental. Políticas Ambientais.

\begin{abstract}
Due to the global concern over environmental management themes, countries began to seek ways to protect their natural resources through policy and environmental management practices in their territories. Seeking better efficiency, the management process is observed decentralization of powers of the federal government to states and municipalities. The creation of environmental policies in Brazil emerged from the Law 6938/81, but only with the Constitution of 1988 that the process of decentralization began. Due to the increasing importance of the subject, studies that seek to describe and detail the process of environmental management in the country are required. This is a descriptive exploratory study with the main objective to analyze how the decentralization of environmental management occurred in the country, presenting some of its main points. Through the data collected, it was concluded that the discussion about the environment had its beginning in 1920/1930, and, despite important landmark in 1960 and 1970, just from 1980s that started the environmental policies and their decentralization process. Currently the country is in set-up process of special departments and agencies in each state to increase management decentralization.

Keywords: Decentralization. Environmental Management. Environmental Policies.

\footnotetext{
${ }^{1}$ Doutorando em Administração (Universidade Federal de Mato Grosso do Sul/Brasil). Professor na Universidade Federal de Mato Grosso do Sul (Cuiabá/Brasil). E-mail: arthur.sanches@ufms.br.

${ }^{2}$ Doutoranda em Engenharia de Produção (Universidade de São Paulo/Brasil). E-mail: marymelo@usp.br.

${ }^{3}$ Doutorando em Engenharia de Produção (Universidade de São Paulo/Brasil). E-mail: willerson.silva@usp.br.

${ }^{4}$ Doutora em Administração (Universidade de São Paulo/Brasil). Professora na Universidade Federal de Mato Grosso do Sul (Cuiabá/Brasil).

E-mail: silviacaleman@gmail.com.
} 


\section{INTRODUÇÃO}

As discussões a respeito da gestão dos recursos naturais e melhor utilização destes vêm ganhando destaque nos estudos realizados nos últimos anos, principalmente a partir da década de 1960, momento de destaque de eventos relacionados também ao contexto social e econômico (GIARETTA; FERNANDES; PHILIPPI, 2012), em razão da crescente preocupação com os conceitos de sustentabilidade e desenvolvimento limpo nos países. Nesse contexto, o Brasil vem implementando algumas políticas que visam melhorar a gestão ambiental em seu extenso território. Contudo, no decorrer dos anos, houve uma descentralização do poder político do governo federal, frente às questões ambientais. Esse poder de decisão de quais políticas seriam adotadas em determinadas regiões do país foi passado aos municípios, os quais, por sua vez, identificam quais ferramentas irão adotar que possam auxiliar na criação de uma gestão ambiental mais eficiente, a qual) está construindo ligações diretas com a sociedade, através de debates e da promoção de troca de conhecimentos (GIARETTA; FERNANDES; PHILIPPI, 2012).

Por fazer parte da história da gestão ambiental que se desenvolve no país, envolvido em formulações e execuções de políticas públicas que passaram de modelos autoritários e burocráticos para processos mais democráticos e participativos (CÂMARA, 2013), justifica-se a realização deste estudo que focaliza a questão da descentralização. Ainda apresenta, de forma detalhada, como a descentralização vem se desenvolvendo no país no decorrer dos anos, a fim de possibilitar que estudos futuros sobre o processo de criação de políticas ambientais no país possam identificar o processo evolutivo de tal ferramenta política.

A contribuição pretendida com o trabalho visa à elaboração de um panorama sobre a evolução da descentralização da gestão ambiental no país, através de uma análise de como tal processo das políticas ambientais se desenvolveu no Brasil ao longo dos anos, especificando como foi o desenvolvimento das transferências de poderes do governo federal para os estados e municípios, permitindo que estes passassem a adotar ferramentas de gestão ambiental distintas. Buscando, de maneira mais específica, conceituar descentralização e políticas ambientais, coletar dados a respeito da descentralização e de como esta evoluiu no país, montar uma linha do tempo que expresse a evolução da descentralização política ambiental e especificar as vantagens do uso da descentralização em âmbito ambiental.

\section{REFERENCIAL TEÓRICO}

O presente estudo traz o tema da gestão ambiental municipal, desde a sua definição aos desafios apresentados por esta, a discussão teórica tem continuidade com o tema governança ambiental, onde são apresentados três subtópicos: transferência de direitos; institucionalidades e regramentos e; descentralização da política ambiental.

\subsection{GESTÃO AMBIENTAL MUNICIPAL}

Philippi, Roméro e Bruna (2004) definem o município como sendo formado por um conjunto de ambientes que mantém um relacionamento entre si, sendo estes: urbano (que abrange a circulação das pessoas, trabalhos, habitação, lazer, saneamento, dentre outras); rural (que abriga, basicamente, o setor primário de produção como atividades agrícolas e minerais); e primevo (que envolve características específicas de cada região, como reservas e a própria identidade do ecossistema). 
No contexto nacional, os municípios só ganharam reconhecimento para as práticas de proteção dos recursos naturais a partir da Constituição Brasileira de 1988, a qual consolidou em solo nacional a questão da preservação do meio ambiente (BRASIL, 1988). Esse marco institucional trouxe uma maior autonomia e competência a tal ente federativo, apontando o município como uma esfera de poder juntamente às esferas estaduais e federais, atribuindo assim, um âmbito de autonomia em suas ações. Meirelles (2013) ressalta que apenas no Brasil o município é reconhecido e considerado como uma parte integrante da Federação, possuindo seu regime como um dos mais aperfeiçoados jurídica e tecnicamente.

A Constituição de 1988 não apenas determinou o papel dos municípios, como também consolidou no país a questão da proteção ambiental, sendo esta essencial à qualidade de vida, como competência de caráter comum aos entes federativos (Art. $23^{\circ}$ ) juntamente com a coletividade. Em adição a isso, deu mais força a Lei Federal nº 6938/81 que estabelece as bases para a Política Nacional do Meio Ambiente, sobretudo no que diz respeito ao cumprimento das diretrizes estabelecidas pelo Sistema Nacional do Meio Ambiente (SISNAMA), concebido como um modelo de gestão ambiental, com foco em articular e harmonizar as ações políticas governamentais no contexto ambiental, assim como implementar a descentralização em todas as esferas do governo (MAGLIO, 2000).

A partir da Resolução Conselho Nacional do Meio Ambiente (CONAMA) nº 237/97 (BRASIL, 1997), os municípios passaram a ter as diretrizes para o exercício do licenciamento ambiental. Esses contam ainda com outros instrumentos para o controle, mitigação e preservação dos impactos ambientais gerados, sendo eles: legais (plano diretor, lei orgânica, código ambiental e uso e ocupação do solo); econômicos (incentivos tributários, fundos municipais do meio ambiente, consórcios municipais); administrativos (unidades específicas para tal temática, parcerias com instituições do setor privado, universidades e entidades afins, capacitação técnica de recursos humanos); e institucionais (Agenda 21, educação ambiental, sistemas de informações ambientais e conselhos de meio ambiente) (GIARETTA; FERNANDES; PHILIPPI, 2012).

Os avanços na formulação de políticas ambientais se devem, em parte, ao envolvimento da sociedade nos assuntos de gestão ambiental, assim como a execução e acompanhamento de projetos. Outros argumentos que surgem em favor da participação são: importância para eficácia das políticas de desenvolvimento; sustentabilidade; boa governança; formação e acumulação de capital social; fortalecimento da sociedade civil e; democratização (COSTA; CUNHA, 2003).

Segundo estudo conduzido por Giaretta, Fernandes e Philippi (2012), dados do perfil dos municípios brasileiros retirados do IBGE em 2008 mostram que ainda há muito a ser melhorado em relação à participação cidadã na gestão ambiental municipal do país, uma vez que menos da metade dos municípios brasileiros $(47,6 \%)$ mantém um conselho municipal do meio ambiente, sendo ainda que 11,6\% apresentam uma formação paritária (governo e sociedade civil) com caráter consultivo a fiscalizador. Contudo, é apontado ainda que, mesmo sendo de caráter consultivo, a participação não pode ser ignorada, uma vez que amplia as oportunidades de manifestar suas escolhas e predileções (GOULART, 2006).

Franco (1999) afirma que o principal desafio da gestão municipal está em assumir seu papel na tentativa de se criar uma nova consciência e novas ações que sejam ambientalmente corretas, rompendo os ciclos e valores previamente expostos como ideais, erroneamente consolidados. Para que isso seja possível, os municípios brasileiros precisam combinar a uma participação democrática com formas de gestão mais eficientes (PACHECO, 1999). Isso deve, ainda, ser colocado junto com um envolvimento da sociedade com a formulação, execução e acompanhamento dos projetos e políticas ambientais, de modo a garantir uma maior equidade articulando as relações entre o local e o global (JACOBI, 1999). 
Fica a cargo do governo incentivar a participação da sociedade, através da promoção de canais abertos. Contudo, é fundamental que a cobrança quanto ao espaço e partilha efetiva do poder exista por parte da sociedade, sem que esta fique apenas esperando a execução do processo, mas sim que busque sua inserção das tomadas de decisão do município (GIARETTA; FERNANDES; PHILIPPI, 2012).

Com o objetivo de ampliar os conhecimentos quanto a governança ambiental brasileira se faz necessária a análise tanto do início do debate a respeito da transferência de direitos, relatando os problemas acerca do custo de transação, quanto do contexto histórico de instituições e regras que antecedem a formulação e execução das políticas que abordam o tema de uso e controle dos recursos naturais, chegando na descentralização dessa política.

\subsection{OS CUSTOS DE TRANSAÇÃO ENVOLVIDOS NA GESTÃO AMBIENTAL}

Coase (1937) em seu trabalho denominado "The Nature of the Firm" discorre a respeito da firma e realiza discussões que serviram como base para muitos estudos posteriores por destacar algo que até então era pouco considerado dentro das transações econômicas do mercado: os custos de transação. De acordo com Kupper e Hasenclever (2002, p. 269) os custos de transação são aqueles "custos que os agentes enfrentam toda vez que recorrem ao mercado", tendo como fatores determinantes: a racionalidade limitada e o oportunismo, a complexidade, a incerteza e a especificidade de ativos.

Dentro de um contexto mais amplo, que abrange desde a formulação de contratos entre empresas, até as limitações existentes para a criação destes como a racionalidade limitada que impede o surgimento de contratos completos, os custos de transação passaram a gerar uma nova ótica na economia, tendo em vista os gastos no momento de se transacionar algo dentro do processo, sejam matérias primas (que podem influenciar na estratégia competitiva da própria organização) ou mesmo na transação de produtos acabados ou entre empresas.

Com isso, diversos estudos passaram a surgir abordando tal tema e explorando novos conceitos dentro das relações econômicas e mesmo políticas, como é o caso de Williamson (1985) o qual afirma que temas complexos, que possuam altos custos de transação, gravitam para a política. Entretanto, sendo determinados assuntos melhor manejados pelo Estado, como no caso das políticas ambientais, sua organização gera certa imobilidade devido aos baixos incentivos, relações de empregos protegidas e custos administrativos altos.

As condições de governança, atreladas aos custos de transação decorrentes da burocracia pública pedem revisões na abordagem da nova economia das organizações à política. Mudanças implantadas há poucos anos na natureza da administração pública possuem componentes de governança que sustentam gestão com controle de custos, transparência financeira, restrições fiscais, autonomia organizacional e descentralização da gestão (WILLIAMSON, 1999).

Direito de Propriedade é como um feixe que engloba os direitos de uso, usufruto e abuso, afastando terceiros que queiram se apropriar dela. Coase (1937) propõe que, na ausência dos custos de transação, a alocação ou distribuição inicial dos direitos de propriedade sobre as dimensões dos bens não terá importância, uma vez que os agentes irão negociar a transferência dos direitos a custo zero, podendo realocá-los eficientemente.

Pelos estudos da Nova Economia Institucional (NEI) e as análises do Direito de Propriedade, ao invés de abrir mão dos ganhos de troca, os agentes econômicos passam a terem incentivos para organizarem suas relações através da criação de instituições que mitiguem os problemas que criam uma barreira às negociações, permitindo que os ganhos do bem-estar sejam realizados. A Análise Econômica do Direito recomenda ainda que a lei deve criar incentivos para que os agentes ajam de forma que resulte 
na mesma alocação de recursos caso os custos de transação fossem baixos. A possibilidade de transferência dos direitos de propriedade afeta diretamente seu valor econômico (SZTAJN; ZYLBERSZTAJN, 2005).

\subsection{INSTITUCIONALIDADES E REGRAMENTOS}

No contexto a respeito das instituições e regramentos existentes que visam proteger e gerenciar de forma mais eficiente as decisões tomadas sobre o meio ambiente, em caráter nacional, pode-se observar a existência de alguns órgãos que trabalham sob tal óptica, como o SISNAMA, CONAMA, atuando em âmbito federal, estadual e municipal, e as secretarias do meio ambiente de cada unidade da federação em particular.

O SISNAMA foi constituído em 31 de agosto de 1981 pela Lei 6.938, sendo regulamentada pelo Decreto 99.274 de 06 de junho de 1990, sendo este constituído pelos órgãos e entidades da União, dos Estados, do Distrito Federal, dos Municípios e pelas Fundações instituídas pelo poder público, responsáveis pela qualidade e melhoria da qualidade do meio ambiente (BRASIL, [20--]).

O SISNAMA atua mediante a articulação coordenada dos Órgãos e entidades que fazem parte de sua constituição, observando o acesso da opinião pública às informações a respeito de agressões sofridas pelo meio ambiente e às ações realizadas para sua preservação, na forma estabelecida pelo CONAMA. Em adição a isso, fica a cargo dos Estados, Distrito Federal e Municípios a regionalização das medidas que partem do SISNAMA, através da elaboração de padrões e normas complementares e supletivos.

O Conselho Nacional do Meio Ambiente (CONAMA) é o órgão consultivo e deliberativo do SISNAMA, tendo sido instituído pela Lei $6.938 / 81$, que dispõe sobre a política nacional do meio ambiente, regulamentada pelo Decreto 99,274/90. A composição do CONAMA é feita pelo Plenário, Comitê de Integração de Políticas Ambientais (CIPAM), Grupos Assessores, Câmaras Técnicas e Grupos de Trabalho. Quem preside o Conselho é o Ministério do Meio Ambiente (MMA) e sua Secretaria Executiva é exercida pelo Secretário Executivo do MMA. As reuniões do CONAMA são realizadas a cada 3 meses no Distrito Federal, podendo ser realizadas reuniões extraordinárias fora deste, sempre que convocada pelo seu presidente.

Deve-se fazer uma diferenciação entre licenciamento ambiental, licença ambiental e estudos ambientais, segundo resolução do CONAMA 237 de 1997:

- Licenciamento Ambiental: procedimento administrativo pelo qual o órgão ambiente competente licencia a instalação, implementação, operação, localização, ampliação e atividade utilizadora de recursos naturais, que sejam consideradas poluidoras, considerando as disposições legais e regulamentares, assim como normas técnicas aplicáveis ao caso.

- Licença Ambiental: ato administrativo do órgão competente que visa estabelecer as condições, restrições, e medidas de controle ambiental que deverão ser seguidas por qualquer empreendedor.

- Estudos Ambientais: são todos e quaisquer estudos relativos aos aspectos ambientais que envolvam localização, instalação, operação e ampliação de atividades apresentadas como subsídio para análise da Licença requerida, como plano e projeto de controle ambiental, relatório ambiental, relatório ambiental preliminar, plano de recuperação da área degradada, plano de manejo, diagnóstico ambiental e análise preliminar de riscos.

- Licenciamento Ambiental Simplificado: procedimento de licenciamento ambiental realizado por intermédio de Comunicado de Atividade, pelo qual o órgão responsável autoriza, de forma concomitante, localização, instalação e operação de atividades que utilizem recursos naturais que sejam causadoras efetivas ou potenciais de impactos no meio ambiente. 


\subsection{DESCENTRALIZAÇÃO DA POLÍTICA AMBIENTAL}

Fernández-Vitora et al. (1997) caracteriza a política ambiental como um conjunto de atividades e procedimentos com os diversos níveis de organizações e competências, de âmbito nacional, do Estado e empresas não governamentais que busquem um determinado fim de proteção e preservação do meio ambiente.

A descentralização, tida como uma forma de estratégia operacional que formula uma nova concepção de políticas públicas tem sido associada com a abertura de canais de participação de atores sociais envolvidos, considerados mecanismos inovadores. Sobre isso, Buarque (1999, p. 16) afirma que:

A descentralização é a transferência da autoridade e do poder decisório de instâncias agregadas para unidades espacialmente menores, entre as quais os municípios e as comunidades, conferindo capacidade de decisão e autonomia de gestão para as unidades territoriais de menor amplitude e escala.

Alguns autores como Silva (1995) e Silva e Costa (1995) tem assinalado que os processos voltados para a descentralização vêm sendo caracterizados, em diversos países, como uma tentativa de reforma administrativa do parâmetro estatal, os quais são determinados de acordo com condições sociais, políticas e econômicas de caráter mundial.

De acordo com diferentes autores (EPSTEIN, 1997; GIBSON; LEHOUCQ, 2003; JOHNSON, 2001; KLIKSBERG, 2000; LIBECAP, 1989; PLATTEAU; GASPART, 2003; PLATTEAU, 2004) existem vantagens e desvantagens no processo de descentralização. No que se diz respeito às vantagens advindas da descentralização, Kliksberg (2000) afirma que estas são derivadas de uma provisão de serviços locais que conduzem a um melhor controle e maior responsabilidade por parte das pessoas que as usam e das comunidades, o que pode ser traduzido como uma melhor gestão social. Já as desvantagens são relativas ao alto dispêndio necessário para se fazer a organização local, bem como os altos custos políticos e aos conflitos entre os próprios usuários locais dos recursos naturais, o que possibilita o risco de haver uma estagnação da gestão dos recursos naturais.

Apresentando um ponto extra na análise sobre a descentralização, pode-se observar as discussões a respeito da terceirização de serviços, uma alternativa para a redução dos custos de transação. Drucker (1992) diz que as empresas sofreram uma reestruturação radical até o final do século, onde as atividades que não representarem partes fundamentais da missão serão subcontratadas, surgindo como consequência de uma busca das empresas por eficiência calcadas em estruturas menores e mais ágeis.

A essência da terceirização é o questionamento sobre fazer ou comprar, e a economia dos custos de transação vem se apresentando como uma área de ampla discussão sobre esse tema (SÁ; BOMTEMPO; QUENTAL, 1998). Embora Coase (1937) seja considerado o criador da discussão a respeito da economia dos custos de transação, Williamson (1979) sistematizou e aprofundou o assunto. Através de sua análise econômica, abordando racionalidade limitada, oportunismo, especificidade dos ativos e incertezas, fez com que a compreensão dos problemas contratuais avançasse (SÁ; BOMTEMPO; QUENTAL, 1998).

Com base nisso, a terceirização pode ser entendida como um mecanismo utilizado para a redução dos custos de transação, permitindo a externalização das atividades, se colocando como uma posição entre hierarquia e o mercado (SÁ; BOMTEMPO; QUENTAL, 1998). 


\section{PROCEDIMENTOS METODOLÓGICOS}

O estudo em questão se caracteriza como histórico descritivo documental. Sobre esse tipo de pesquisa, Baruffi (2002) afirma que a pesquisa histórica é caracterizada pelo registro, análise e interpretação dos acontecimentos do passado com o propósito de descobrir generalizações que possam ter valia para estudos presentes e futuros. Tais pesquisas, em seus procedimentos metodológicos, manejam as categorias fundamentais do trabalho do historiador, os quais são: temporalidade, espacialidade e agentes sociais. O enfoque se dá na mudança, no desenvolvimento dos indivíduos, de grupo, de práticas e de ideias e instituições. As principais técnicas utilizadas nesse tipo de pesquisa são: coleta de dados históricos ou coleta de documentos; a crítica histórica (interna e externa); e a síntese.

No presente estudo utilizou-se como principal fonte bibliográfica as leis e decretos publicados em sites oficiais, bem como as informações disponibilizadas pelas secretarias do meio ambiente, a fim de permitir uma melhor compreensão sobre o processo de descentralização das políticas ambientais no Brasil. Em complemento, utilizou-se artigos científicos advindos do Google Scholar, por ser uma base menos restritiva, permitindo assim uma maior quantidade de material disponível; teses e dissertações voltadas ao tema advindas da Biblioteca Digital Brasileira de Teses e Dissertações (BDTD) e; documentos técnicos do Ministério do Meio Ambiente (MMA) e do Instituto Brasileiro do Meio Ambiente e dos Recursos Naturais Renováveis (IBAMA).

A pesquisa descritiva, por sua vez, possui como objetivo principal descrever, analisar, registrar, interpretar e correlacionar fatos ou fenômenos. Tal pesquisa não busca manipular variáveis, mas sim toma os dados como eles são apresentados na natureza, tentando descobrir, de forma precisa, a frequência com que determinado fenômeno ocorre, suas características e natureza, assim como a conexão que este pode possuir com outros fenômenos distintos (BARUFFI, 2002). Nesta pesquisa a análise dos dados será feita por meio da descrição, onde serão relacionados os tópicos abordados no referencial teórico com a história identificada pela análise documental, visando sintetizar os principais marcos históricos e apresentar como estes moldaram a realidade do presente (SÁ-SILVA; DE ALMEIDA; GUINDANI, 2009).

Como limitação deste método destaca-se o vínculo entre a disponibilidade de informações claras e completas com a profundidade da análise pois, por se tratar de um evento político, para se analisar a questão da descentralização o pesquisador fica dependente da disponibilidade de materiais por parte do Estado. Tal fato é sabidamente crítico, tendo em vista a morosidade na divulgação das informações e os entraves para acessá-las (SIMÃO; RODRIGUES, 2005), sendo as informações que deveriam ser públicas, muitas vezes ocultas quando buscadas a fundo.

\section{ANÁLISE E DISCUSSÃO DOS RESULTADOS}

Como apontado por Câmara (2013) em estudo realizado a respeito da descentralização das políticas ambientais no Brasil desde o século XVIII, a partir do ano de 1930, a economia brasileira tem sido submetida a um processo de desenvolvimento muito pautado no pensamento desenvolvimentista em que o progresso é visado a qualquer custo, visando sempre o desenvolvimento da economia (DRUMMOND, 1999). A partir da coalizão entre as classes médias, de operários, e as políticas industrialistas surge a regulamentação pública sobre os recursos naturais no ano de 1920, o que levou a Revolução de 1930. A integração (nacional e societária) decorrente deste momento marcou o começo de um período caracterizado pelo controle federal sobre o uso e ocupação do território e de seus recursos 
naturais, ocorrendo uma disputa de hegemonia entre forças políticas e a elite econômica local de diferentes estados e o governo central (NEDER, 2002).

Após a década de 1930, a legislação florestal sofreu grandes transformações, e vem se transformando de uma legislação estritamente florestal e de cunho econômico para uma ambiental de caráter mais pontual. Tal transformação vem ocorrendo em razão da edição de códigos com o intuito de proteção, tendo sido diversificado o controle do Estado sobre os recursos naturais disponíveis. Entretanto, ainda se observam a manutenção de estruturas oligárquicas que mantém sua influência na governança dos temas voltados ao meio ambiente. Câmara (2013, p. 130) afirma que:

[...] desse processo resultaram legislações que regulamentaram o uso dos recursos naturais como: o Código das Águas (Decretos $\mathrm{n}^{\circ} 24.643 / 34, \mathrm{n}^{\circ} 24.672 / 34, \mathrm{n}^{\circ} 13 / 35$ e Decreto-Lei ${ }^{\circ}$ 852/38); Código Florestal (Decreto $n^{\circ}$ 23.793/37); Parques Nacionais (1937); Proteção ao Patrimônio Histórico e Artístico Nacional (1937); Código de Pesca (Decreto-Lei no 794/38 e Decreto-Lei no 1.631/39); Código de Minas (DecretoLei $\mathrm{n}^{\circ}$ 1.895/40); Código das Águas Minerais (Decreto-Lei nº 7.841/45).

No relativo à fauna brasileira, o Decreto $n^{\circ} 24.645 / 34$ trouxe pouca inovação, uma vez que manteve a fauna sob a tutela do Estado. Soma-se a isso o fato de nenhuma das constituições do país serem declarados como bens da União (NÉTO, 1999). Com a chegada do Código Civil de 1916 os animais passaram a ser tratados como coisas que não possuem dono e estão sujeitos a apropriação (Código Civil, art. 593) de forma que o animal passa a ser posse daquele que o apreende (Código Civil, art. 595) (NÉTO, 1999).

Neder (2002 apud CÂMARA, 2013) diz que o começo da governança dos recursos naturais se caracterizou ações do Governo que fomentavam o incentivo e o financiamento à produção, buscando induzir a conversão de princípios dessas leis em moeda econômica entre o governo central e as elites locais. Dessa forma, foram estabelecidos, nesse período, fortes relações de poder em uma estrutura centralizada, piramidal-hierárquica com conflitos, dinâmicas intra e inter-regionais e interesses, que se reproduzem ao longo das décadas seguintes.

No que tange os recursos naturais, houve tendência da regulação independente e não integrada dos seus usos, a partir de 1930, acarretando em políticas setorizadas que atendiam a grupos de interesse diversos. Muitas vezes houve conflitos sobre a utilização dos recursos naturais e disputas políticas com ações isoladas, descoordenadas e dissociadas da vontade da maior parte dos atores sociais (CÂMARA, 2013).

Foi somente a partir dos anos de 1960 e 1970 que, com a intensificação do processo de industrialização no país, o Brasil passou a obter maior engajamento da sociedade nos temas ambientais e sociais, possivelmente devido às consequências desastrosas verificadas com a poluição industrial e contaminação de áreas urbanas nas proximidades, o que acabou por resultar em graves problemas de saúde à população local. $\mathrm{O}$ enfoque segmentado da questão ambiental no país, agravada por uma legislação fragmentada e individualizada por tipo do recurso natural ou seu uso sofreu modificação a partir de 1970, principalmente após a I Conferência das Nações Unidas sobre Meio Ambiente, realizada em Estocolmo. Nesse momento foi criada a Secretaria Especial do Meio Ambiente (SEMA) e elaborada uma regulamentação de temas ambientais integrados como recursos hídricos, poluição, flora e fauna (ALMEIDA; CAVALCANTI; MELLO, 2000).

No início dos anos 80 foram realizados no Brasil os primeiros estudos de avaliação dos impactos ambientais, uma exigência do Banco Interamericano de Desenvolvimento (BID) e do Banco Internacional para Reconstrução e Desenvolvimento (BIRD), uma parte do Banco Mundial. Contudo, uma vez que o país não possuía, ainda, normas ambientais próprias, os estudos foram realizados 
seguindo normas de exigências internacionais. Movimentos sociais se movimentaram nessa época, contrários ao ritmo das degradações ambientais, gerando certas articulações entre esses e outros organismos internacionais, acarretando pressões políticas que passaram a ameaçar o fluxo de investimentos vindos do estrangeiro os quais sustentavam parte dos programas de desenvolvimento do Governo Federal, criando a necessidade de uma profunda revisão no contexto político-institucional no início desse período (CÂMARA, 2013).

A necessidade que surgiu frente aos desafios dos problemas ambientais existentes contribuiu para o surgimento da Política Nacional do Meio Ambiente, instituída pela Lei 6.938/81, a qual estabeleceu diretrizes para tal política, assim como seus instrumentos de implementação, buscando destacar e exigência, em âmbito nacional, do licenciamento ambiental de atividades que façam uso de recursos naturais e que possam ser consideradas efetiva ou potencialmente causadoras de poluição (CÂMARA, 2013).

Esse contexto político-institucional foi o que propiciou o estabelecimento de uma malha de instituições federais, municipais e estaduais focadas na gestão ambiental dos recursos naturais, o que acabou por ampliar o número de participantes na composição do processo decisório.

Autores como Franco (1999) destacam justamente os desafios que gestões municipais enfrentam, em especial quando se trata da utilização de recursos naturais, possuindo todo um desafio voltado para a criação de novas consciências e ações ambientalmente aceitas. Nesse contexto, a ampliação de participantes na composição do processo decisório pode aproximar as mudanças da população, principal alvo das mudanças, fazendo com que a transformações de suas ações possam acontecer de forma mais rápida por conta da integração do desenvolvimento no processo de decisão.

No que tange o uso de tais recursos, essa participação foi ampliada de forma mais efetiva com a instituição da gestão participativa e ao se assegurar maior diversidade de atores sociais envolvidos no planejamento e uso desses recursos determinados. A utilização do Estudo de Impacto Ambiental (EIA) e do Relatório de Meio Ambiente (Rima) no país estabeleceu mecanismos que favoreceram a governança ambiental, introduzindo as audiências públicas no processo de licenciamento ambiental, permitindo que as populações interessadas, ou afetadas por empreendimentos que causassem impactos ambientais pudessem se manifestar. Na política ambiental, os instrumentos de comando e controle são considerados de regulação direta, uma vez que implicam em controle sobre o local onde está sendo emitido o poluente. Assim, o órgão regulador estabelece um conjunto de normas e procedimentos, padrões e regras a serem seguidos pelos agentes que emitem poluição, do mesmo modo que impõem penalidades distintas como multas e o cancelamento da licença e embargos caso descumpram o previamente estabelecido (CÂMARA, 2013).

A partir de 1988, a atual constituição traz, pela primeira vez, a preocupação com o meio ambiente, abrangendo uma série de dispositivos que tratam da questão ambiental e da qualidade de vida (arts. 225, 231, 232 e arts. 196 a 204). Os avanços trazidos por essa constituição em diversos aspectos do direito passaram a elevar os municípios à condição de unidade federada, estabelecendo a repartição de competências assim como a previsão do direito do meio ambiente. Essa nova classificação traz novos traços de ordem política e jurídica aos municípios, notadamente quanto a sua autonomia, seu governo e sua capacidade de auto-organização (o que pode ser visto nos arts. 23, 24, 30 e 225 da Constituição Federal) (SCARDUA; BURSZTYN, 2003).

Quanto à questão do federalismo das constituições brasileiras e seu formato, Souza (1992) resume em seu trabalho como visto na Quadro 1. 
Quadro 1 - Federalismo nas constituições brasileiras

\begin{tabular}{|c|c|c|c|c|c|c|}
\hline & \multicolumn{6}{|c|}{ ANOS } \\
\cline { 2 - 7 } & 1891 & 1934 & 1937 & 1946 & $1967-1969$ & 1988 \\
\hline Centralizador (União) & & $\mathrm{X}$ & $\mathrm{X}$ & $\mathrm{X}$ & $\mathrm{X}$ & \\
\hline Centralizador (estado-membro) & $\mathrm{X}$ & & & & & \\
\hline Municipalista & & $\mathrm{X}$ & & $\mathrm{X}$ & & \\
\hline Partilha do Poder & & & & & & $\mathrm{X}$ \\
\hline
\end{tabular}

Fonte: Souza (1992)

A partir dos anos 90, observou-se um processo de liberação da economia brasileira, criando uma forte ofensiva contra a responsabilidade ambiental que vinha sendo imposta pelo Estado. Os idealistas de tal liberação exigiam um Estado enxuto e mínimo, ao passo em que atacavam o sistema de licenciamento ambiental, acusando-o de ser lento e fraco, associando tais problemas à falta de emprego no país (ACSELRAD, 2005).

Em 1990 foi aprovado o Programa Nacional de Meio Ambiente (PNMA), sendo iniciado em setembro de 1991, pelo IBAMA, com acompanhamento da SEMA. Em princípio, o programa foi concebido com apenas três linhas temáticas, que envolviam o desenvolvimento institucional do IBAMA e MMA e manejo e estruturação de unidades de conservação. Contudo, em 1994, após a revisão de Meio Termo do Programa, uma nova temática foi incorporada, sendo ela "Projetos de Execução Descentralizada (PED)" que seriam executados pelos estados. Esse programa possuía como objetivo o fortalecimento institucional da gestão ambiental em todos os níveis do governo, sendo que todos os subcomponentes do programa PNMA possuíam ações voltadas à descentralização ambiental de forma indireta, exceto pelo subcomponente denominado "Unidades de Conservação". Já o "PED" tratava da questão de forma direta, diferentemente dos demais (SCARDUA, 2003).

Também em 1994, teve início em fevereiro o Programa de Descentralização da Gestão Ambiental, o qual possuía como instituições patrocinadoras o IBAMA e o MMA. Seu objetivo era o de descentralizar as atividades desempenhadas pelo Governo Federal, para os Estados, de forma conjunta, articulada e participativa, de acordo com os preceitos da constituição de 1988. O início de tal programa aponta para a necessidade que o país enfrentava de reformas na administração de tal gestão, incluindo condições políticas, sociais e econômicas, como destacado por alguns autores sobre processos de descentralização em diversos países (SILVA, 1995; SILVA; COSTA, 1995).

De maneira mais detalhada, o programa possuía como objetivos: definir áreas de descentralização da Política ambiental no Brasil, formando parcerias com os Estados e municípios da federação, através de órgãos ambientais locais; fortalecer institucionalmente os órgãos componentes do SISNAMA, tornando possível sua implementação efetiva; definir áreas que sejam prioritárias na atuação dos órgãos do SISNAMA, nos diversos níveis do governo; criar subsídios para o aperfeiçoamento da legislação ambiental federal, visando definir as competências dos diferentes níveis de governo na execução da gestão ambiental descentralizada; avaliar e definir fontes de recursos para o fortalecimento institucional dos OEMAs, assim como a manutenção das atividades delegadas ou transferidas; e, por fim, definir as atividades e procedimentos a serem realizadas pelo IBAMA e MMA, focando no monitoramento e controle das atividades de gestão ambiental (SCARDUA, 2003).

No que tange a descentralização através das parcerias com estados e municípios, o país é colocado como um destaque nas questões técnicas e jurídicas, em decorrência dos municípios serem considerados 
uma parte integrante da Federação, como sugere Maglio (2000). Em razão do desenvolvimento precoce em tais áreas, a questão envolta da distribuição de poderes das esferas maiores do governo para localidades mais específicas já vinha sedimentada em estruturas mais sólidas compostas pela própria imagem técnica e jurídica das unidades menores da Federação.

Na primeira parte do programa foram formuladas algumas propostas: fortalecimento institucional dos órgãos do SISNAMA; divulgação de informações; legislação (esclarecendo e definindo competências específicas de cada esfera do governo); educação ambiental; conservação de ecossistemas; gestão ambiental urbana; maior articulação entre órgãos que formulam políticas ambientais sobre os recursos hídricos; unidades de conservação; recursos florestais (ampla revisão da política florestal); revisão do aparato normativo referente à legislação da fauna e flora; formulação e revisão da política pesqueira; participação do Estado na formulação de programas nacionais; instrumentos de controle e fiscalização ambiental; propor a criação de um sistema de licenciamento ambiental unificado; fiscalização; e instrumentos para a descentralização. A segunda etapa previa a implementação do programa por meio da constituição de um grupo de trabalho, contudo o mesmo não teve continuidade (SCARDUA, 2003).

O detalhamento da primeira parte de implementação do programa consiste com as vantagens advindas dos processos de descentralização como exposto por Kliksberg (2000). O autor destaca que a descentralização prove de serviços locais que acarretam um maior controle e responsabilidade por parte das pessoas que fazem uso de tais bens e de suas comunidades. Nesse contexto observa-se a importância da maior divulgação de informações e a preocupação com a educação ambiental, acarretando em uma gestão de caráter mais social.

Scardua (2003) em sua tese apresenta os resultados de uma pesquisa a respeito do grau de descentralização das políticas ambientais no Brasil até o ano em questão. Com isso é possível analisar como o processo passou a se desenvolver nos últimos anos, partindo da existência de secretarias específicas para tratar do meio ambiente em cada unidade da federação. A criação destas não indica, necessariamente, uma melhora no trato da gestão ambiental, mas sim a relevância dada pelo poder executivo à questão ambiental. Até 2003, dezoito estados apresentaram possuir secretarias especificas do meio ambiente, sendo eles: AC, RO, PA, AP, PI, PB, PE, SE, SP, MG, ES, RJ, MS, GO, DF, SC, PR e RS.

Embora certa cautela seja necessária quando se trata das melhorias geradas pela descentralização no que tange de fato a gestão ambiental, esse aumento na criação de secretarias específicas nos estados aponta para uma terceirização das atividades de controle da utilização e manutenção dos recursos naturais. Considerando o que Sá, Bomtempo e Quental (1998) indica sobre a capacidade de tal ferramenta na redução dos custos de transação, e o complemento dado por Williamson (1999) em suas análises sobre as mudanças implementadas na administração pública (que permitem uma melhor transparência financeira, além de controle de custos e autonomia organizacional), as possibilidades de mudanças e melhorias começam a se tornar mais realistas e próximas.

Desse total de 27 estados, 24 estados implementaram legislações específicas no que tange os recursos hídricos, 18 fizeram o mesmo para recursos florestais, e apenas 3 para unidades de conservação. Em relação aos conselhos (participação, composições e atribuições), 25 estados apresentaram conselhos estaduais deliberativos. Já no contexto dos Pactos Federativos, estes foram firmados com os estados de: MG, GO, CE, MT, BA e ES, estando ainda em negociação nos estados da PB, SC, PE, RO e PR.

Seguindo os critérios selecionados para o estudo, Scardua (2003) avalia o grau de descentralização da Gestão Ambiental no país, como pode ser observado na Tabela 1. 
Tabela 1 - Grau de descentralização da Gestão Ambiental no Brasil no ano de 2003

\begin{tabular}{|c|c|c|}
\hline \multirow{2}{*}{ CRITÉRIOS } & \multicolumn{2}{|c|}{$\mathrm{N}^{\circ}$ DE ESTADOS } \\
\hline & Possui & Não possui \\
\hline Existência de Secretarias específicas para tratar de meio ambiente & 18 & 9 \\
\hline Implementação do licenciamento ambiental & 27 & 0 \\
\hline Implementação da Gestão de Recursos Hídricos & 24 & 3 \\
\hline Implementação da Gestão de Recursos Florestais & 18 & 9 \\
\hline Implementação da Gestão de Unidades de Conservação (UC) & 3 & 24 \\
\hline $\begin{array}{l}\text { Participação, composição e atribuições (consultivo/deliberativo) nos respectivos Conselhos } \\
\text { Estaduais de Meio Ambiente }\end{array}$ & 25 & 2 \\
\hline Repasse de Atribuições para os estados via Pacto Federativo & 6 & 21 \\
\hline MÉDIA ARITMÉTICA PONDERADA & $64 \%$ & $36 \%$ \\
\hline
\end{tabular}

Fonte: Scardua (2003)

Através do que foi visualizado anteriormente, podemos observar que, num contexto geral, $64 \%$ dos estados do país apresentam algum grau de descentralização em suas políticas ambientais, já os outros $34 \%$ ainda buscam formas de cumprir com os critérios estipulados pelo estudo.

Tal resultado aponta para uma das desvantagens do processo de descentralização exposta por diversos autores (EPSTEIN, 1997; GIBSON; LEHOUCQ, 2003; JOHNSON, 2001; KLIKSBERG, 2000; LIBECAP, 1989; PLATTEAU; GASPART, 2003; PLATTEAU, 2004), a grande quantidade de dispêndios que se fazem necessários para a organização local. Embora mais da metade dos estados apresentem algum grau de descentralização frente às suas políticas ambientais, possíveis conflitos políticos gerados, alto custo político, bem como conflitos que possam surgir entre os usuários locais dos recursos são algumas das barreias que podem dificultar o desenvolvimento de tal gestão nos demais entes da federação, ou mesmo limitar a descentralização naqueles estados que já deram os passos iniciais no processo de mudança.

Atualmente, todos os 26 estados, mais o Distrito Federal, já contam com Conselhos do Meio Ambiente, como pode ser observado no Quadro 2, com sua nomenclatura e localização da maioria dos conselhos.

Quadro 2 - Conselhos do Meio Ambiente

\begin{tabular}{|l|l|}
\hline \multicolumn{1}{|c|}{ ESTADOS } & \multicolumn{1}{c|}{ CONSELHOS DE MEIO AMBIENTE } \\
\hline ACRE & Conselho Estadual do Meio Ambiente (Rio Branco) \\
\hline ALAGOAS & Conselho Estadual de Proteção Ambiental - CEPRAM (Maceió) \\
\hline AMAZONAS & Conselho Estadual do Meio Ambiente e Desenvolvimento Sustentável \\
\hline AMAPÁ & Conselho Estadual de Meio Ambiente (Macapá) \\
\hline BAHIA & Conselho Estadual de Meio Ambiente " CEPRAM (Salvador) \\
\hline CEARÁ & Conselho Estadual do Meio Ambiente - COEMA (Fortaleza) \\
\hline DISTRITO FEDERAL & Conselho Estadual do Meio Ambiente - CONAN (Brasília) \\
\hline ESPÍRITO SANTO & Conselho Estadual do Meio Ambiente do Espírito Santo \\
\hline GOIÁS & Conselho Estadual de Meio Ambiente - CEMAm (Goiânia) \\
\hline MARANHÃO & Conselho Estadual de Meio Ambiente (São Luís) \\
\hline MINAS GERAIS & Conselho de Política Ambiental - COPAM (Belo Horizonte) \\
\hline MATO GROSSO DO SUL & Conselho Estadual de Controle Ambiental " CECA (Campo Grande) \\
\hline MATO GROSSO & Conselho Estadual de Meio Ambiente (Cuiabá) \\
\hline
\end{tabular}




\begin{tabular}{|l|l|}
\hline \multicolumn{1}{|c|}{ ESTADOS } & \multicolumn{1}{c|}{ CONSELHOS DE MEIO AMBIENTE } \\
\hline PARÁ & Conselho Estadual de Meio Ambiente - COEMA (Belém) \\
\hline PARAÍBA & Conselho de Proteção Ambiental Estadual - COPAM (João Pessoa) \\
\hline PERNAMBUCO & Conselho Estadual de Meio Ambiente - CONSEMA (Recife) \\
\hline PIAUÍ & Conselho Estadual de Meio Ambiente - CONSEMA (Teresina) \\
\hline PARANÁ & Conselho Estadual de Meio Ambiente (Curitiba) \\
\hline RIO DE JANEIRO & Conselho Estadual de Meio Ambiente - CONEMA (Rio de Janeiro) \\
\hline RIO GRANDE DO NORTE & Conselho Estadual de Meio Ambiente - CONEMA (Natal) \\
\hline RONDÔNIA & Conselho Estadual do Meio Ambiente (Porto Velho) \\
\hline RORAIMA & Conselho Estadual do Meio Ambiente, Ciência e Tecnologia - CEMACT (Boa Vista) \\
\hline RIO GRANDE DO SUL & Conselho Estadual de Meio Ambiente - CONSEMA (Porto Alegre) \\
\hline SANTA CATARINA & Conselho Estadual de Meio Ambiente - CONSEMA (Florianópolis) \\
\hline SERGIPE & Conselho Estadual do Meio Ambiente - CONSEMA (Aracaju) \\
\hline SÃO PAULO & Conselho Estadual de Meio Ambiente - CONSEMA (São Paulo) \\
\hline TOCANTINS & Conselho Estadual do Meio Ambiente - COEMA (Palmas) \\
\hline
\end{tabular}

Fonte: elaborado pelos autores baseado em Brasil (2014)

Em adição a isso, o Ministério do Meio Ambiente ainda disponibiliza informações a respeito dos secretários de meio ambiente (Quadro 3) de cada estado, mostrando como as questões voltadas à política ambiental em cada estado vêm se desenvolvendo cada vez mais.

Quadro 3 - Secretários do Meio Ambiente

\begin{tabular}{|c|c|c|}
\hline ESTADOS & $\begin{array}{c}\text { SECRETÁRIOS DE MEIO } \\
\text { AMBIENTE }\end{array}$ & DESCRIÇÃO \\
\hline ACRE & Eufran Ferreira do Amaral & $\begin{array}{c}\text { Secretário Estadual de Ciência, Tecnologia e Meio } \\
\text { Ambiente - SECTMA }\end{array}$ \\
\hline ALAGOAS & Ana Catarina Pires Azevedo Lopes & $\begin{array}{c}\text { Secretário executiva de Meio Ambiente e Rec. } \\
\text { Hídricos e Naturais - SEMARH }\end{array}$ \\
\hline AMAZONAS & Virgílio Maurício Viana & $\begin{array}{l}\text { Secretário de Estado de Meio Ambiente e } \\
\text { Desenvolvimento Sustentável do Amazonas }\end{array}$ \\
\hline AMAPÁ & Marcelo Ivan Pantoja Creão & $\begin{array}{c}\text { Secretário Estadual do Meio Ambiente, Ciência e } \\
\text { Tecnologia - SEMA }\end{array}$ \\
\hline BAHIA & Juliano Sousa Matos & $\begin{array}{c}\text { Secretário Estadual do Planejamento, Ciência e } \\
\text { Tecnologia }\end{array}$ \\
\hline CEARÁ & Tereza Farias & Secretaria da Ouvidoria Geral e Meio Ambiente \\
\hline DISTRITO FEDERAL & Rubens Martins & $\begin{array}{l}\text { Secretário Estadual de Meio Ambiente e Recursos } \\
\text { Hídricos do Distrito Federal -SEMARH }\end{array}$ \\
\hline ESPÍRITO SANTO & Maria Da Gloria B. Abaurre & $\begin{array}{c}\text { Secretário Estadual para Assuntos do Meio } \\
\text { Ambiente - SEAMA }\end{array}$ \\
\hline GOIÁS & Roberto Gonçalves Freire & $\begin{array}{c}\text { Secretário Estadual do Meio Ambiente e Recursos } \\
\text { Hídricos - SEMARH }\end{array}$ \\
\hline MARANHÃO & Othelino Nova Alves Neto & $\begin{array}{c}\text { Secretário de Meio Ambiente e Recursos Naturais } \\
\text { do Estado do Maranhão - SEMA }\end{array}$ \\
\hline MATO GROSSO & Luis Henrique Chaves Daldegan & $\begin{array}{c}\text { Secretário Estadual de Ciência e Tecnologia e Meio } \\
\text { Ambiente - SEMA }\end{array}$ \\
\hline MATO GROSSO DO SUL & Carlos Alberto Negreiros Said Menezes & $\begin{array}{c}\text { Secretário Estadual do Meio Ambiente, Cultura e } \\
\text { Turismo - SEMACT }\end{array}$ \\
\hline
\end{tabular}




\begin{tabular}{|c|c|c|}
\hline ESTADOS & $\begin{array}{l}\text { SECRETÁRIOS DE MEIO } \\
\text { AMBIENTE }\end{array}$ & DESCRIÇÃO \\
\hline MINAS GERAIS & José Carlos Carvalho & $\begin{array}{l}\text { Secretário Estadual de Meio Ambiente e } \\
\text { Desenvolvimento Sustentável - SEMADES }\end{array}$ \\
\hline PARÁ & Anibal Pessoa Picanço & Secretário de Estado de Meio Ambiente - SEMA \\
\hline PARAÍBA & Francisco Jacome Sarmento & $\begin{array}{l}\text { Secretário Estadual da Secretária da Ciência e } \\
\text { Tecnologia e Meio Ambiente }\end{array}$ \\
\hline PARANÁ & Luiz Eduardo Cheida & $\begin{array}{c}\text { Secretário Estadual de Meio Ambiente e Recursos } \\
\text { Hídricos do Paraná - SEMA }\end{array}$ \\
\hline PERNAMBUCO & Fátima Maria Miranda Brayner & $\begin{array}{c}\text { Secretária Executiva da Secretaria de Meio } \\
\text { Ambiente e Recursos Hídricos }\end{array}$ \\
\hline PIAUÍ & Dalton Melo Macambira & $\begin{array}{l}\text { Secretário Estadual do Meio Ambiente e dos } \\
\text { Recursos Hídricos - SEMAR }\end{array}$ \\
\hline RIO DE JANEIRO & Luiz Paulo Fernandez Conde & $\begin{array}{l}\text { Secretário Estadual de Meio Ambiente e } \\
\text { Desenvolvimento Sustentável - SEMADS }\end{array}$ \\
\hline $\begin{array}{l}\text { RIO GRANDE DO } \\
\text { NORTE }\end{array}$ & $\begin{array}{c}\text { Francisco Vagner Gutemberg De } \\
\text { Araujo }\end{array}$ & $\begin{array}{l}\text { Secretário de Estado do Planejamento e das } \\
\text { Finanças }\end{array}$ \\
\hline RIO GRANDE DO SUL & José Alberto Wenzel & Secretário Estadual do Meio Ambiente - SEMA \\
\hline RONDÔNIA & Augustinho Pastore & $\begin{array}{l}\text { Secretário Estadual do Desenvolvimento Ambiental } \\
\qquad- \text { SEDAM }\end{array}$ \\
\hline RORAIMA & Clidenor Andrade Leite & $\begin{array}{l}\text { Secretário Estadual de Planejamento, Indústria, } \\
\text { Comércio e Meio Ambiente - SEPLAN }\end{array}$ \\
\hline SANTA CATARINA & Sérgio De Souza Da Silva & $\begin{array}{c}\text { Secretário Estadual do Desenvolvimento Urbano e } \\
\text { Meio Ambiente - SDM }\end{array}$ \\
\hline SÃO PAULO & José Goldemberg & Secretário Estadual do Meio Ambiente - SMA \\
\hline SERGIPE & $\begin{array}{l}\text { Maria do Socorro Barros Andrade } \\
\text { Cacho }\end{array}$ & Secretário Especial do Meio Ambiente - SEMA \\
\hline TOCANTINS & Lívio William Reis de Carvalho & $\begin{array}{c}\text { Secretário do Estadual do Planejamento e Meio } \\
\text { Ambiente do Estado de Tocantins }\end{array}$ \\
\hline
\end{tabular}

Fonte: elaborado pelos autores baseado em Brasil (2014)

A existência de tantos conselhos voltados a cada estado, juntamente com a criação de cargos de secretários do meio ambiente para essas localidades indicam o progresso do processo de descentralização, mostrando que, cada vez mais, o poder sobre as decisões da gestão ambiental está deixando de ficarem concentradas no Governo Federal.

\section{CONSIDERAÇÕES FINAIS}

Através do que foi analisado e estudado sobre a descentralização no Brasil, podemos observar que seu processo ainda continua em andamento, sendo esta cada vez mais presente nos estados e municípios da federação através de programas, legislações e implementação de políticas que visam tratar do meio ambiente de uma forma mais adequada e criteriosa.

O processo teve início entre 1920 e 1930 quando a política de desenvolvimento econômico do país acabou por gerar preocupações a respeito do uso dos recursos naturais. A partir de então o tema foi sendo, cada vez mais, incorporado pela população e o governo passou a assumir uma postura mais atenta às questões ambientais na década de 60 e 70, chegando a criar a Secretaria Especial do Meio Ambiente (SEMA). 
Contudo, os processos voltados à gestão ambiental passaram a se intensificar mesmo a partir de 1981, com a criação da Lei 6.938/81 que definiu as diretrizes para a formulação de políticas ambientais no Brasil, criando uma base mais sólida para o contexto que já vinha sendo discutido.

Estando estabelecidas as estruturas para a criação das políticas ambientais, foi a partir da Constituição Federal de 1988 que o processo de descentralização da gestão ambiental brasileira começou a ter destaque, uma vez que a nova constituição em si trabalha as formas de governança de maneira mais descentralizada. Isso se seguiu na década seguinte, quando foi criado o Programa Nacional de Meio Ambiente (PNMA) pelo IBAMA e SEMA e também projetos voltados especialmente para a descentralização, como o Projeto de Execução Descentralizada (PED).

A partir de então a descentralização da gestão ambiental brasileira vem se desenvolvendo aos poucos, com a criação de secretarias e implementação de políticas nos estados e municípios, buscando tratar de questões como a utilização dos recursos hídricos, recursos florestais e a criação de unidades de conservação.

Com isso conclui-se que o processo de descentralização no Brasil teve seu início mais propriamente dito a partir de 1988 com a chegada da nova Constituição Federal, possuindo marcos importantes na década de 90 e se desenvolvendo até os dias de hoje, com um processo complexo de transferência das atribuições do governo federal aos estados e municípios da federação.

\section{REFERÊNCIAS}

ACSELRAD, H. Apresentação. In: LASCHEFSKI, A.; PEREIRA, D. B.; ZHOURI, A. (Eds.). A Insustentável Leveza da Política Ambiental: Desenvolvimento e Conflitos Socioambientais. Belo Horizonte: Autêntica, 2005. p. 7.

ALMEIDA, J. R.; CAVALCANTI, Y.; MELLO, C. DOS S. Gestão ambiental: planejamento, avaliação, implantação, operação e verificação. Rio de Janeiro: Thex, 2000.

BARUFFI, H. Metodologia da pesquisa: manual para a elaboração da monografia. 3. ed. Dourados: Hbedit, 2002.

BRASIL. O que é o Conama?: SISNAMA - Sistema Nacional do Meio Ambiente. Ministério do Meio Ambiente. [20--].

BRASIL. Constituição da República Federativa do Brasil. Brasília: Senado Federal, 1988.

BRASIL. Resolução n ${ }^{\circ} 237$ do Conselho Nacional do Meio Ambiente, de 19 de dezembro de 1997. Estabelece critérios para o licenciamento ambiental pelo município. Diário Oficial da República Federativa do Brasil, Poder Executivo, Brasília, DF, 1997.

BRASIL. Conselhos de Meio Ambiente. Ministério do Meio Ambiente. 2014.

\section{BUARQUE, S. C. Metodologia de planejamento do desenvolvimento local e municipal} sustentável. Brasilia: IICA, 1999.

CÂMARA, J. B. D. Governança ambiental no Brasil: ecos do passado. Revista de Sociologia e Política, v. 21, n. 46, p. 125-146, 2013.

COASE, R. H. The nature of the firm. economica, v. 4, n. 16, p. 386-405, 1937.

COSTA, F. L. DA; CUNHA, A. P. G. Pensar o desenvolvimento a partir do local: novo desafio para os gestores públicos. In: VERGARA, S. C.; CÔRREA, V. L. A. (Eds.). Propostas para uma gestão pública municipal efetiva. Rio de Janeiro: FGV, 2003. p. 17-37. 
DRUCKER, P. F. Managing for the future: the 1990s and beyond. New York: Truman Talley/Dutton, 1992.

DRUMMOND, J. A. A legislação ambiental brasileira de 1934 a 1988: comentários de um cientista ambiental simpático ao conservacionismo. Ambiente \& sociedade, v. 2, n. 4, 1999.

EPSTEIN, R. A. Enforcing norms: When the law gets in the way. Responsive Community, v. 7, p. 4 $15,1997$.

FERNÁNDEZ-VITORA, V. C. Los instrumentos de la gestión ambiental en la empresa. Madrid: Mundi-Prensa, 1997.

FRANCO, R. M. Principais problemas ambientais municipais e perspectivas de solução. In: PHILIPPI JÚNIOR, A. et al. (Eds.). Municípios e meio ambiente: perspectivas para a municipalização da gestão ambiental no Brasil. São Paulo: ANAMMA, 1999. p. 19-32.

GIARETTA, J. B. Z.; FERNANDES, V.; PHILIPPI, A. Desafios e condicionantes da participação social na gestão ambiental municipal no Brasil. Organ. Soc., v. 19, n. 62, p. 527-550, 2012.

GIBSON, C. C.; LEHOUCQ, F. E. The local politics of decentralized environmental policy in Guatemala. The Journal of Environment \& Development, v. 12, n. 1, p. 28-49, 2003.

GOULART, J. O. Orçamento participativo e gestão democrática no poder local. Lua Nova, v. 69, p. 49-78, 2006.

JACOBI, P. Poder local, políticas sociais e sustentabilidade. Saúde e Sociedade, v. 8, n. 1, p. 31-48, 1999.

JOHNSON, C. Community formation and fisheries conservation in Southern Thailand. Development and Change, v. 32, n. 5, p. 951-974, 2001.

KLIKSBERG, B. Cómo reformar el Estado para enfrentar los desafíos sociales del 2000. Revista de la Facultad de Ciencias Económica, v. 5, n. 6, p. 235-269, 2000.

KUPPER, D.; HASENCLEVER, L. Economia industrial: fundamentos teóricos e práticos no Brasil. Rio de Janeiro: Campus, 2002.

LIBECAP, G. D. Distributional issues in contracting for property rights. Journal of Institutional and Theoretical Economics (JITE)/Zeitschrift für die gesamte Staatswissenschaft, v. 145, n. 1, p. 624, 1989.

MAGLIO, I. C. A descentralização da gestão ambiental no Brasil: o papel dos órgãos estaduais e as relações com o poder local, 1990/1999. 2000. 270 f.Dissertação (Mestrado em Saúde Pública) Faculdade de Saúde Pública, Universidade de São Paulo, São Paulo, 2000

MEIRELLES, H. L. Direito municipal brasileiro. 14. ed. São Paulo: Malheiros, 2013.

NEDER, R. T. Crise socioambiental: estado \& sociedade civil no Brasil, 1982-1998. São Paulo: Annablume, 2002.

NÉTO, J. M. B. Crimes Ambientais da Lei n. 9.605: Competência federal ou estadual. Boletim dos Procuradores da República-ANPR, n. 13, 1999.

PACHECO, R. S. Administração pública gerencial: desafios e oportunidades para os municípios brasileiros. In: FUNDAÇÃO PREFEITO FARIA LIMA-CEPAM (Ed.). O município no século XXI: cenários e perspectivas. São Paulo: Especial, 1999. p. 39-50. 
PHILIPPI JÚNIOR, A.; ROMÉRO, M. A.; BRUNA, G. C. Uma introdução à questão ambiental. In: PHILIPPI, A., JR., ROMÉRO, M. A.; BRUNA, G. C. (Eds.). Curso de gestão ambiental. Barueri: Manole, 2004. p. 3-16.

PLATTEAU, J. Monitoring elite capture in Community- Driven development. Development and Change, v. 35, n. 2, p. 223-246, 2004.

PLATTEAU, J.-P.; GASPART, F. The risk of resource misappropriation in community-driven development. World development, v. 31, n. 10, p. 1687-1703, 2003.

SÁ-SILVA, J. R.; DE ALMEIDA, C. D.; GUINDANI, J. F. Pesquisa documental: pistas teóricas e metodológicas. Revista brasileira de história e ciências sociais, v. 1, n. 1, p. 1-15, 2009.

SÁ, M. P.; BOMTEMPO, J. V.; QUENTAL, C. Terceirização no processamento final da indústria farmacêutica e veterinária. Revista de Administração Contemporânea, v. 2, n. 2, p. 85-101, 1998.

SCARDUA, F. P. Governabilidade e descentralização da gestão ambiental no Brasil. 2003. 256 f.Tese (Doutorado em Política e Gestão Ambiental)-Centro de Desenvolvimento Sustentável, Universidade de Brasília, Brasília, 2003

SCARDUA, F. P.; BURSZTYN, M. A. A. Descentralização da política ambiental no Brasil. Sociedade e Estado, v. 18, n. 1-2, p. 291-314, 2003.

SILVA, P. L. B. Descentralização de políticas sociais: marco teórico e experiências internacional e brasileira. In: VELLOSO, J. P. R.; ALBUQUERQUE, R. C.; KOOP, J. (Eds.). Políticas sociais no Brasil: descentralização, eficiência e equidade. Rio de Janeiro: Inae/Ildes, 1995.

SILVA, P. L. B.; COSTA, V. L. C. Descentralização e crise da Federação. In: AFFONSO, R. B. Á.; SILVA, P. L. B. (Eds.). A Federação em perspectiva: ensaios selecionados. São Paulo: FUNDAP, 1995. p. 261-283.

SIMÃO, J. B.; RODRIGUES, G. Acessibilidade às informações públicas: uma avaliação do portal de serviços e informações do governo federal. Ciência da Informação, v. 34, n. 2, p. 81-92, 2005.

SOUZA, C. M. Democracia, participação social e funcionamento das instituições: situação e perspectivas da federalização do desenvolvimento. Revista de Administração Pública, v. 26, n. 3, p. 15-35, 1992.

SZTAJN, R.; ZYLBERSZTAJN, D. Direito e economia. São Paulo: Campus Elsevier, 2005.

WILLIAMSON, O. The Economic Institutions of Capitalism. New York: Free Press, 1985.

WILLIAMSON, O. Public and private bureaucracies: a transaction cost economics perspectives. Journal of Law, Economics, and Organization, v. 15, n. 1, p. 306-342, 1999.

WILLIAMSON, O. E. Transaction-cost economics: the governance of contractual relations. The journal of Law and Economics, v. 22, n. 2, p. 233-261, 1979. 